https://cssr.uitm.edu.my/2018/

5th International Conference on Science and Social Research Le Meridien Kota Kinabalu Hotel, 5 - 6 December 2018

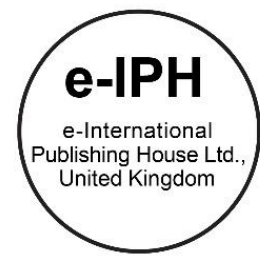

\title{
User Experience (UX) and User Interface (UI) as a New Recipe of Academic Culture in Creative Industry
}

\author{
Andi Nursyuhada Abdul Kadir 1, Raja Ahmad Azmeer Raja Ahmad Effendi 2 , \\ Mohd Shahrizal Dolah 2, Saiful Hasley Ramli 2
}

1 Department of Industrial Design, Faculty of Creative Technology, Universiti Malaysia Kelantan, 16300 Bachok Kelantan, Malaysia
2 Department of Industrial Design, Faculty of Design and Architecture, Universiti Putra Malaysia, 43400 Serdang Selangor, Malaysia

andi.ak@umk.edu.my, azmeer@upm.edu.my, shahrizal@upm.edu.my,shr@upm.edu.my

Tel: +60182714531

\begin{abstract}
This preliminary study aims to introduce User Experience (UX) and User Interface (UI) as a new recipe that could be implemented in academic culture to make sure the adaptation human and technology will be more effective and improve the creative industry. This study uses a survey questionnaire on purposive sampling to investigate the knowledge perception of 30 design practitioners and structured interview of 9 random samplings to know their perspectives. This study concluded that $60 \%$ of design practitioners realize the needs of this new approach, while the interview leads to the three main themes: acceptance level, vitality awareness and tendency expectation.
\end{abstract}

Keywords: Design Emotion, User Experience, User Interface, Academic Culture, Creative Industries

eISSN: 2398-4287O 2020. The Authors. Published for AMER ABRA CE-Bs by e-International Publishing House, Ltd., UK. This is an open access article under the CC BYNC-ND license (http://creativecommons.org/licenses/by-nc-nd/4.0). Peer-review under responsibility of AMER (Association of Malaysian Environment-Behaviour Researchers), ABRA (Association of Behavioural Researchers on Asians) and cE-Bs (Centre for Environment-Behaviour Studies), Faculty of Architecture, Planning \& Surveying, Universiti Teknologi MARA, Malaysia.

DOI: https://doi.org/10.21834/ebpj.v5iSI3.2551

\subsection{Introduction}

The new era of development that involve acceleration of technology and rapid social change make people need to move and adapt to the environment that exposed to be very digitalized. Because of that, in the situation of new recipes needed in the food industry to have a portion of better food and conquer the market, the creative industry also needs new recipes in academic culture to have a desirable life. Adapting technology to human nature in the dawn of the industrial revolution is synonymous with the dramatic increases of advance technology that impact industrial productivity. Both paradoxes rapidly rose up in current studies that highlight the technology value as a tool to achieve whatever is concerned pleasurable (Hassenzahl, 2008). Even this revolution had been seen as something that enlightened human and product interaction on smaller and intelligent boxes, the mechanism of it still facing difficulties, as Bolz (2000) mentioned since years ago. This leads to the commence of the best approach on how technology could be used positively in many recent studies especially when Industry 4.0 became hit and growing attention in Europe and many countries, over the globe (Evans et al., 2012; Blanchet et al., 2014).

eISSN: 2398-4287@ 2020. The Authors. Published for AMER ABRA cE-Bs by e-International Publishing House, Ltd., UK. This is an open access article under the CC BYNC-ND license (http://creativecommons.org/licenses/by-nc-nd/4.0/). Peer-review under responsibility of AMER (Association of Malaysian Environment-Behaviour Researchers), ABRA (Association of Behavioural Researchers on Asians) and cE-Bs (Centre for Environment-Behaviour Studies), Faculty of Architecture, Planning \& Surveying, Universiti Teknologi MARA, Malaysia. DOI: https://doi.org/10.21834/ebpj.v5iSI3.2551 
Recently, the Industry 4.0 phenomenon triggered by the development of Information and Communications Technology (ICT). In fact, the used smart automation of cyber-physical system as the technological basis with decentralized control and advanced connectivity on the Internet of Things (loT) functionalities (Rojko, 2017). Impact of it, the focus on technology understanding directed to the production of smart products. Based on Beckert (2014), a smart product capable of perceiving and interacting with their physical environment. It also supported by Schmidt et al. (2015) that today smart products not only cater to their identity but also depict their history, properties, status and ability to communicate information on their lifecycle. Indirectly, there are many fields started to focus on this direction, including the creative industry that already predicted by Jensen (1999) where users are expecting more from everyday products since years ago.

\subsection{Literature Review}

Increasing competitive integration of physical and digital world that combines big data analytics with the Internet of Things give impact to the creative industry on being rapidly transformed to adapt with it (Rojko, 2017). Juster and Fitchie (2002) believed the competitive situation makes approach, style, quality and brand image increasingly became attention to distinguish the products. Meanwhile, in the academic world, many of these concerns have been discussed since a decade by researchers like Ohira (1995) and Jones (1997) that believed design occurs in every single way with strong reference to the lifestyle, emerging with the environmental, implemented of technology and fulfil the customer-oriented trends.

Because of that, in order to embark with the current society of data-based, one of the best contributions in academic culture is by implementing user experience (UX) and user interface (UI) understanding as a new recipe to enhance the creative industry. Based on Kim and Cho (2016), User Experience (UX) attributes to the whole experience related to the perception when the user feels and thinks through the use of the system, product, content or service. While User Interface (UI) related to interfacing that through appearance, use commands or techniques to operate the system, input data and content usage (Heon-sik, 2015).

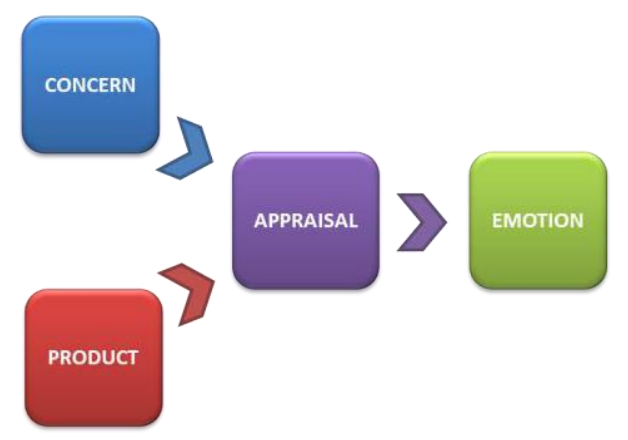

Figure 1 Basic Model of Product Emotion by Desmet, 1990

(Von Saucken et al., 2013) stated that User Experience (UX) enhances the User Interface (UI) through blended of the emotional aspect. Some studies have been done to take a more systematic profound approach, and this has resulted in product designs that address the connection between design and emotion as shown in Figure 1(e.g. Desmet \& Dijkhui, 2003; Hekkert et al., 2003). Over the past years, significant interest in design and emotion has been imbued within design practice and design research. According to Moore (2002), people desire is not actually the product; instead, it is the satisfying emotions. Thus, emotion gives an astounding impact on the generation, development, production, purchase intention (Mc Donagh, 2004).

In the nowadays creative and technical environment and development, the terms "UX" (User Experience) and "UI" (User Interface) started been widely used more than ever. All in all, these terms are referring to the specialities and ideas which are known to be around for quite some time now suited to the introduction of the abbreviated terminology respectively. Despite the fact that people often use these terms, there are still a lot of people out there who never stumble upon the terminologies mistook these terms to share similar meaning which actually does not. Ed Lea (2012) as one of UX designer then made a simple analogy to show an easy understanding of how UX and UI work as shown in Figure 2

Thus, the research has been carried out to measure the understanding of $\mathrm{UX}$ and $\mathrm{UI}$ among design practitioner due to the crucial and importance of it to be a new recipe in academic culture. 




Product

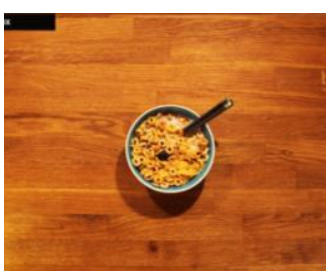

UX



UI

Figure 2 Understanding of User Experience (UX) and User Interface (UI) by Ed Lea, 2012

\subsection{Methodology}

A set questionnaire that consisted of design understanding, differentiation of UX UI and the recognition of UX UI application in the latest creative industry was distributed to the purpose sampling of 30 design practitioners that consist of 10 design lecturer, ten designer and ten design students to enhance the quality of research findings. Before the questionnaires are distributed, a pilot study will be done among the selected small group of about 20 design practitioners to test the reliability of the questionnaire.

Among design practitioners, there will be a three random sampling respondent chosen from each categorizes of lecturer, designer and student to answer semi-structured interviews about UX and UI followed by thematic analysis of the interview data. A set of questions was designed in order to guide the course of interviews. These questions were not presented to the participants, but it uses as a general guide in order to have a smooth conversation.

These questions tackle the following theme that corresponds to the purpose of this study: The participants' general knowledge on Understanding of $\mathrm{UX} \mathrm{UI,} \mathrm{the} \mathrm{importance} \mathrm{of} \mathrm{UX} U \mathrm{U}$ and the influence of $\mathrm{UX} \mathrm{UI}$ in the creative industry. The audio from the interviews was digitally recorded. Thematic analysis was performing on the collected audio data, and the participants answer according to the themes mentioned.

\subsection{Findings}

\subsection{Questionnaire}

The questionnaire was divided into five sections which section A covered the Respondent Profile, Section B General Design Understanding, Section $\mathrm{C}$ about UX and UI understanding, Section D touch on differentiation UX UI and Section E about Recognizing element of $U X U I$ in the creative industry. The results sum up in the chart below;

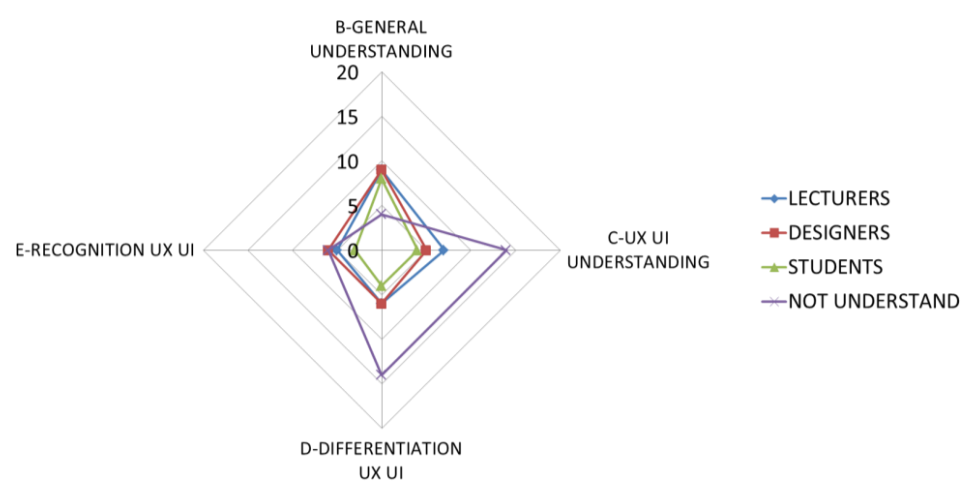

Chart 1: The overall result from thequestionnaires

Table 1: The overall result from thequestionnaires

\begin{tabular}{|lcccc|}
\hline & LECTURER & DESIGNER & STUDENT & UNCERTAINTY \\
\hline A RESPONDENT PROFILE & 10 & 10 & 10 & N/A \\
B GENERAL DESIGN & 9 & 9 & 8 & 4 \\
UNDERSTANDING & 7 & 5 & 4 & 14 \\
C UX UI UNDERSTANDING & 6 & 6 & 4 & 14 \\
D DIFFERENT OF UX UI & 5 & 6 & 3 & 16 \\
E RECOGNITION ELEMENTUX & & & 3 \\
UI IN CREATIVE INDUSTRY & & & & 14 \\
\hline
\end{tabular}




\subsection{Structured Interview}

All the interviews are based on the objective of the research. The respondent's background is divide by three, which are from academician, industry and design students.

Table 2: The interview result of the understanding of (UX\&UI) in the creative industry

\section{Research Question 1:}

To examine to what extend the understanding of (UX\&UI) in the creative industry.

\begin{tabular}{ll}
\hline Academician & $\begin{array}{l}\text { Our local design industries are still in the stage of accepting the UX\&UI. This is } \\
\text { because they do not realize the importance and contribution of UX\&UI in market. }\end{array}$ \\
\hline Industry & $\begin{array}{l}\text { There are still numbers of design practitioners who do not fully understand about } \\
\text { the term of UX\&UI because of the lack number of UX\&UI experts. }\end{array}$ \\
\hline Design students & $\begin{array}{l}\text { Designers are aware of the terms of UX\&UI, but they are not familiar to their } \\
\text { principles and applications. }\end{array}$
\end{tabular}

Research Question 2:

Table 3: The interview result of the importance of (UX\&UI) in the creative industry

To identify the importance of (UX\&UI) in the creative industry

\begin{tabular}{ll}
\hline Academician & $\begin{array}{l}\text { As for academician, he said that the importance of UX\&UI in product design could } \\
\text { improve the design performance }\end{array}$ \\
\hline Industry & $\begin{array}{l}\text { The UX\&UI are the main elements in order to develop new products because they involved the } \\
\text { expectation, perception and the direct emotion that may fulfil the } \\
\text { needs of users. }\end{array}$ \\
\hline Design students & UX\&UI can be seen as an added value to the products. \\
\hline
\end{tabular}

Table 4: The interview result of the influence of (UX\&UI) in the creative industry

Research Question 3:

To investigate the influence of (UX\&UI) in the creative industry

\begin{tabular}{ll}
\hline Academician & $\begin{array}{l}\text { How people use their automotive and what are the expectations coming from the experience from the } \\
\text { users }\end{array}$ \\
\hline Industry & It is all about the expectation that UX Designers wish to know \\
\hline Design students & $\begin{array}{l}\text { UX\&Ul can be seen as women's makeup which it evokes emotions in terms of } \\
\text { confidence level or satisfaction }\end{array}$ \\
\hline
\end{tabular}

\subsection{Discussion}

\subsection{Questionnaire}

Based on the pilot study of 20 design practitioners, there is the expectation that most of the design practitioner really has a good understanding on general design understanding of UX and UI but very difficult to justify its implementation in our daily life, especially in transportation perspective. Chart 1 and Table 1 show the overall result from the questionnaires. In section B, there are 26 design practitioners (87\%) that really score very well in term of general design understanding like Aesthetic, Usability and Technical and only 4 of them (13\%) that a bit confuses on the role of element and principle of design.

As we can see in the section $C$ and $D$, this is the important question on how to investigate the understanding of design practitioners on UX and UI by describe the familiar with the term and know to differentiate between two of it. There is the number of design practitioner that understands the UX and UI with those who do not have any idea about it by only $53 \%$ understand the term while another $47 \%$ do not understand the term and misconfused it. While the result in section $\mathrm{E}$ shows that most of the design practitioners cannot recognize well the implementation of UX and UI creative industry. Only $47 \%$ can understand it well, and the rest just understand it after exposed with the explanation on how UX and UI applied daily life situation.

The overall result of this study concluded $60 \%$ of the design practitioners realize the needs of the new approach, the importance of it and how it will drive our daily life in a positive way while another $40 \%$ uncertainty on how it works. Specifically, the respondents were familiar with the terms of UX and UI. They also believed that Design, Identity and Philosophy are very important in product development. Respondents many products in daily life and also agreed to the importance of Aesthetic, Usability and Technical. But they were still confused with differentiating between UX and UI applications in the creative industry.

Respondents a bit confusing to identify the UX and UI elements from illustrations given but they were belief the role of UX and $\mathrm{UI}$ in the creative industry really important and could be a new recipe in academic culture especially in design. The 
respondents wished to have good experiences, and they believed that good implantation of UX and UI would give a big contribution to the new generation in the future that really close to technology development.

\subsection{Structured Interview}

From the structured interview, three themes were identified as acceptance level, vitality awareness and tendency expectation. The acceptance level represents the understanding of design practitioner on User Experience (UX) and User Interface (UI) that shows they are really familiar with the term in creative industry and directly highlight the vitality awareness since they realize the importance of UX $\mathrm{UI}$ could improve the implementation of technology in daily life. The tendency expectation represents the influences of UX UI in the creative industry as a new approach that will help humanity in many ways.

\subsection{Conclusion \& Recommendations}

Based on the results from the study, this research concluded that most of the respondents used the automotive in their daily life without realizing the role of (UX\&UI). Most of the respondents agreed and believed that UX\&UI are essential and play an important role in the creative industry. However, there are still design practitioners who do not understand clearly about UX\&UI applications.

As a recommendation, the industries and users should be aware of the importance of UX\&UI by recognizing the application of UX\&UI in our daily life. Significantly, the information and knowledge regarding UX and UI are very beneficial and will become a tremendous contribution to the development of our local creative industries.

\section{Acknowledgements}

The authors gratefully acknowledge Dr Raja Ahmad Azmeer Raja Ahmad Effendi and all committee member for the invaluable help and support, as well as the people in the faculty of design and architecture, University Putra Malaysia.

\section{References}

Basat, S., Tentzeris, M. M., \& Laskar, J. (2006). Design and development of a miniaturized embedded UHF RFID tag for automotive tire applications. 2006 IEEE International Workshop on Antenna Technology, IWAT 2006 - Small Antennas and Novel Metamaterials,2006(1),160-163.

Chen, L. L., Kang, H. C., \& Hung, W. K. (2007). Effect of design features on automobile styling perceptions. International Association of Societies of Design Research, 12-15

Da Silva, O., Crilly, N., \& Hekkert, P. (2015). How people's appreciation of products is affected by their knowledge of the designers' intentions. International Journal of Design, 9(2), 21-33.

Divall, C., \& Revill, G. (1998). No Title, 1(March 2005), 99-111.

Dowlen, C., \& Shackleton, J. (2003). Design History Of The Car : An Empirical Overview Of The Development Of Layout And Form A General Overview of Car History Methods. International Conference on Engineering Design ICED 03 Stockholm. Desmet, P.M.A., \& Hekkert, P. (2002). The basis of product emotions. In: W. Green and P. Jordan (Eds.), Pleasure with Products, beyond usability (60-68). London: Taylor \& Francis.

Desmet, P., Hekkert, P., \& Hillen, M. (2003). Values and Emotions; an Empirical Investigation in the relationship between emotional responses to products and human value.

Desmet, P., \& Hekkert, P. (2007). Framework of product experience. International Journal of Design, 1(1), 57-66. https://doi.org/10.1162/074793602320827406 Dix, A., Finlay, J., Abowd, G. D., \& Beale, R. (2005). Human-Computer Interaction.

Eyben, F., Wöllmer, M., Poitschke, T., Schuller, B., Blaschke, C., Färber, B., \& Nguyen-Thien, N. (2010). Emotion on the road-Necessity, acceptance, and feasibility of affective computing in the car. Advances in Human-Computer Interaction, 2010. https://doi.org/10.1155/2010/263593

Fleming, J., \& Koman, R. (1998). Web navigation: designing the user experience, 288

Garrett, J. J. (2003). The Elements of User Experience: User-Centered Design for the Web and Beyond, Second Edition. Gomez, R., \& Bucolo, S. (2005). Driving : The Emotional Experience and Automotive Design.

Grondelle, E. D. Van, \& Dijk, M. B. Van. (2004). Educating automotive design: a scientific approach without compromising tacit knowledge. International Engineering and Product Design Education Conference, (September), 1-8.

Hekkert, P. (2006). Design aesthetic: principles of pleasure in design (157-172). Psychology Science. Kadous, M. W., Sheh, R. K., \& Sammut, C. (2006). Effective User Interface Design for Rescue Robotics.

Law, E. L.-C., Roto, V., Hassenzahl, M., Vermeeren, A. P. O. S., \& Kort, J. (2009). Understanding, scoping and defining user experience. Proceedings of the 27th International Conference on Human Factors in Computing Systems - CHI 09, (April 2016), 719. https://doi.org/10.1145/1518701.1518813 
Leder, H., \& Nadal, M. (2014). Ten years of a model of aesthetic appreciation and aesthetic judgements: The aesthetic episode- Developments and challenges in empirical aesthetics. British Journal of Psychology, 105, 443-464

McAdams, D. A., \& Kostovich, V. (2011). A framework and representation for universal product design. International Journal of Design, 5(1), 29-42. Myers, B., Hudson, S. E., \& Pausch, R. (2000). Past, Present, and Future of User Interface Software Tools, 7(1), 3-28.

Operating Costs Differentiation Among the Haulage. (2009), (April).

Radford, S. K., \& Bloch, P. H. (2011). Linking Innovation to Design: Consumer Responses to Visual Product Newness. Product Development \& Management Association. J Prod Manag, 28(1), 208-220.

Rubmann. M., Lorenz. M., Gerbert. P., Waldner. M., Justus. J., Engel. P., \& Harnisch. M. (2015) Industry 4.0: The Future of Productivity and Growth in Manufacturing Industries.

Sarani, R., Roslan, A., \& Saniran, N. (2011). Motorcycles. Malaysian Institute of Road Safety Research(Miros) ADSA FACT SHEET VOL. 1 May 2011, Vol. 1(Issue : May), pp: 1-6.

Schelp, L., \& Svanstrom, L. (1987). A model for registration and mapping of accident cases in health care. Scandinavian Journal of Primary Health Care, 5(2), 91-99. http://doi.org/10.3109/02813438709013983

Shneiderman, B., \& Plaisant, C. (2010). Designing the User Interface: Strategies for Effective Human-Computer Interaction. Pearson. https://doi.org/10.1016/0166- 3615(93)90066-A

Sodemann, H., Palmer, a. S., Schwierz, C., Schwikowski, M., \& Wernli, H. (2005). The transport history of two Saharan dust events archived in an Alpine ice core. Atmospheric Chemistry and Physics Discussions, 5(4), 7497-7545. http://doi.org/10.5194/acpd-5-7497-2005

Van Mierlo, J., Maggetto, G., \& Lataire, P. (2006). Which energy source for road transport in the future? A comparison of battery, hybrid and fuel cell vehicles. Energy Conversion and Management, 47(17), 2748-2760. http://doi.org/10.1016/j.enconman.2006.02.004

Warell, A., \& The, A. (2005.). Visual experience of brand-specific automobile design : Studying appreciation, emotion and comprehension using the VPE framework. October, (2005).

Yoon, J., Desmet, P. M. A., \& van der Helm, A. (2012). Design for interest: Exploratory study on a distinct positive emotion in human-product interaction. International Journal of Design, 6 (2), 67-80. 